\title{
Valoración del estado nutricional de los pacientes con Enfermedad Renal Crónica ingresados en la unidad de nefrología
}

\author{
Carlota Hidalgo López, Marisol Fernández Chamarro, Gloria García Gallardo, Mª Teresa Baz Rodríguez, \\ Silvia Collado Nieto, Ernestina Junyent Iglesias
}

Hospital del Mar. Barcelona

\section{Introducción:}

La desnutrición proteico-calórica es una complicación frecuente en los pacientes con Enfermedad Renal Crónica (ERC). Estudios recientes inciden en la desnutrición como un marcador que disminuye la calidad de vida de estos pacientes y aumenta su morbimortalidad.

\section{Objetivos:}

Evaluar el estado nutricional de los pacientes ingresados en nuestra unidad de nefrología y valorar su evolución durante el ingreso. Valorar el porcentaje de ingesta de la dieta pautada durante el ingreso a través de un registro.

\section{Método:}

Estudio prospectivo y observacional de los pacientes ingresados en nuestra unidad de nefrología durante 6 meses excluyendo ingresos inferiores a $72 \mathrm{~h}$. Se analizan parámetros analíticos y antropométricos como albúmina y proteína $C$ reactiva (PCR), Valoración Global Subjectiva (VSG), Simpliified Nutritional Appetite Questionnaire (SNAQ) y bioimpedancia al ingreso y al alta. Se realiza un registro alimentario donde se apunta el porcentaje de ingesta diaria.

\section{Resultados:}

Se incluyeron a 92 pacientes, con una media de edad de $61.42+20.57$, un $55.9 \%$ hombres y un $44.1 \%$ mujeres, con un IMC de $28.6+7.3 \mathrm{Kg} / \mathrm{m}$ y con una estan- cia hospitalaria media de $11.79+7.78$ días. Se dividen en 4 grupos: $26.4 \%$ eran pacientes IRC agudizada sin tratamiento sustitutivo, un $9.9 \%$ IR Aguda, un 28.6 $\%$ en diálisis (hemodiálisis o diálisis peritoneal) y un $35.2 \%$ trasplantados renales. El $67.7 \%$ eran diabéticos. Al ingreso un $60,4 \%$ de los pacientes presentan niveles de albúmina $<3.5 \mathrm{mg} / \mathrm{dl}$ y en el momento del alta en un $57.6 \%$, en cambio la escala VSG sólo detectó un $33.7 \%$ de malnutrición al ingreso y un 32.1\% al alta. Los pacientes diabéticos tenían niveles más bajos de albúmina de manera significativa ( $p=0.044)$, mayor edad $(p=0.021)$, mayor peso $(p=0.033)$ y una estancia hospitalaria más prolongada $(p=0.014)$. Al analizar las bioimpedancias observamos que los pacientes en diálisis presentan reducción significativa de la masa grasa ( $p=0.033)$, y aumento del agua corporal al alta $(p=0.032)$, presentando mayor estancia hospitalaria el subgrupo de malnutrición $(p=0.001)$. La ingesta media de los pacientes durante el ingreso fue del 78,28\% Si correlacionamos la ingesta con SNAQ al alta vemos, que los pacientes con $S N A Q>14$ presentan una ingesta media del $81,77 \%$, mientras que los $S N A Q<14$ su ingesta media es de $73,92 \%$.

\section{Conclusiones:}

La prevalencia de malnutrición en nuestra población es muy elevada, incluso por encima de lo que la bibliografía cita. En nuestra población las escalas de nutrición: SNAQ y VSG detectan menos pacientes desnutridos, por lo que la valoración analítica y la bioimpedancia se considerarían instrumentos más sensibles y pueden ser muy útiles. Aunque las cifras de malnutrición son del $60 \%$ únicamente un 
$10 \%$ de los pacientes recibieron suplementos nutricionales. El $50 \%$ de los pacientes presentan un SNAQ $<14$ al alta, observamos cómo sus ingestas diarias son inferiores en todas las comidas y que va disminuyendo durante el día, siendo la menor en la cena. Nos planteamos profundizar en el análisis de esta situación para realizar las intervenciones de enfermería.

\section{Referencias Bibliográficas}

1. Planas $M$, Álvarez J, García A, Celaya S, León M, García-Lorda P, Brosa M. The burden of hospital malnutrition in Spain: methods and development of the PREDyCES ${ }^{\circledR}$ study. Nutr Hosp. 2010;25(6):1020-1024.

2. Kondrup J, Johansen N, Plum LM, Bak L, Larsen IH, Martinsen A et al. Incidence of nutritional risk and causes of inadequate nutritional care in hospitals. Clin Nutr2002; 21: 461-8.

3. Rashidi AA, Soleimani AR, Nikoueinejad H, Sarbolouki $S$. The evaluation of increase in hemo- dialysis frequency on C-reactive protein levels and nutritional status. Acta Med Iran. 2013 Mar 16;51(2):119-24.

4. Bravo Ramírez AM, Chevaile Ramos A, Hurtado Torres GF. Composición corporal en pacientes con insuficiencia renal crónica y hemodiálisis. Nutr Hosp. 2010;25(2):245-249.

5. Mendías Benítez C, Alonso de Porras L, Barcia García J, Sánchez Oliva JM, Jiménez Quintana $E$, Lara Ruiz A, Chaín de la Bastida J. Bioimpedancia eléctrica. Diferentes métodos de evaluación del estado nutricional en un centro periférico de hemodiálisis. Rev Soc Esp Enferm Nefrol 2008; 11 (3): 173/177.

6. Gutiérrez Martín $C$, Mayoral Peñas A, Velasco Ballestero S. Prevalencia y detección de la desnutrición en pacientes en diálisis en la unidad de nefrología del Hospital General de Segovia. Rev Soc Esp Enferm Nefrol 2009; 12 (4): 274/281.

7. Fernández-Reyes MJ, Álvarez-Ude F, Sánchez R, Mon C, Iglesias $P$, Vázquez A. Estado nutricional comorbilidad e inflamación en hemodiálisis. Nefrología 2000; 20: 540-549. 